\title{
Congelação de sêmen equino após 24 horas de resfriamento
}

\author{
Freezing equine semen after 24 hours of cooling \\ Congelación de semen equino después de 24 horas de enfriamiento
}

Recebido: 04/11/2020 | Revisado: 08/11/2020 |Aceito: 11/01/2021 | Publicado: 14/01/2021

\author{
Rogéria Werner de Almeida Coelho \\ ORCID: https://orcid.org/0000-0002-6709-4852 \\ Instituto Federal do Norte de Minas Gerais, Brasil \\ E-mail: rogeria_wac@hotmail.com \\ Júlio César Oliveira Dias \\ ORCID: https://orcid.org/0000-0002-9356-4264 \\ Instituto Federal do Norte de Minas Gerais, Brasil \\ E-mail: diasjuliovet@yahoo.com.br
}

\begin{abstract}
Resumo
O objetivo com este trabalho é trazer de forma técnica o método de resfriação e congelação de espermatozoides da espécie equina após a refrigeração por $24 \mathrm{~h}$ com quatro diluidores comerciais. A abordagem técnica vai desde os exames que antecedem e comprovam a viabilidade do garanhão para coleta até o descongelamento de amostras. A coleta é realizada por meio de vagina artificial modelo para equinos e manequim para monta do animal. Após a coleta e análise das características macroscópicas (cor, aspecto, odor e volume) e microscópicas (motilidade total, vigor e concentração espermática) do sêmen fresco, será realizado o resfriamento das amostras seminais, à $5^{\circ} \mathrm{C}$, por 24 h, com os diluentes comerciais. Após esse período, as amostras serão centrifugadas e o pellet será ressuspendido com diluente comercial para congelamento e criopreservado à $-196^{\circ} \mathrm{C}$ em palhetas. As palhetas serão descongeladas à 37 ${ }^{\circ} \mathrm{C}$ para serem usadas em inseminação artificial.
\end{abstract}

Palavras-chave: Inseminação artificial; Resfriamento e congelamento de sêmen; Viabilidade do garanhão.

\begin{abstract}
The objective of this work is to bring about technically the equine sperm cooling and freezing method after $24 \mathrm{~h}$ refrigeration with four commercial diluents. The technical approach ranges from the tests that precede and prove the viability of the stallion for collection to the thawing of samples. The collection is performed by means of artificial model vagina for horses and animal dummy. After collecting and analyzing the macroscopic (color, appearance, odor and volume) and microscopic (total motility, vigor and sperm concentration) characteristics of fresh semen, seminal samples will be cooled at $5^{\circ} \mathrm{C}$ for $24 \mathrm{~h}$. commercial diluents. After this period, the samples will be centrifuged and the pellet will be resuspended with commercial freezing diluent and cryopreserved at $-196{ }^{\circ} \mathrm{C}$ in straws. The blades will be thawed at $37^{\circ} \mathrm{C}$ for use in artificial insemination.
\end{abstract}

Keywords: Artificial insemination; Semen cooling and freezing; Stallion viability.

\section{Resumen}

El objetivo de este trabajo es acercar de forma técnica el método de enfriamiento y congelación de espermatozoides de la especie equina después de refrigeración durante $24 \mathrm{~h}$ con cuatro diluyentes comerciales. El enfoque técnico va desde los exámenes que preceden y prueban la viabilidad del semental para la recolección hasta la descongelación de las muestras. La recogida se realiza mediante un modelo de vagina artificial para caballos y un maniquí para montar al animal. Después de recolectar y analizar las características macroscópicas (color, apariencia, olor y volumen) y microscópicas (motilidad total, vigor y concentración espermática) del semen fresco, las muestras seminales se enfriarán a $5{ }^{\circ} \mathrm{C}$ durante $24 \mathrm{~h}$ con el diluyentes comerciales. Pasado este período, las muestras se centrifugarán y el pellet se resuspendirá con diluyente comercial para congelación y se criopreservará a $-196^{\circ} \mathrm{C}$ en pajillas. Las pajitas se descongelarán a $37^{\circ} \mathrm{C}$ para su uso en inseminación artificial.

Palabras clave: Inseminación artificial; Enfriamiento y congelación de semen; Viabilidad del semental.

\section{Introdução}

No Brasil a equinocultura tem se desenvolvido muito nos últimos anos, em segmentos, como os esportes, essa cultura possui representatividade internacional. Outra área que vem ganhando destaque é o turismo rural, aumentando as opções de renda com a utilização do cavalo. Bahia e Minas Gerais possuem os maiores rebanhos, e a região Centro-Oeste é a que possui maior crescimento exponencial. Isso coloca o Brasil com um dos maiores efetivos do mundo. O uso do cavalo tem gerado 
empregos, de forma indireta 3,2 milhões e movimentando um montante de 7,5 bilhões de reais por ano na economia nacional (Lima et al., 2012).

A biotecnologia da reprodução é uma importante ferramenta a serviço da equideocultura mundial, como instrumento direto do melhoramento genético. Levando em consideração as vantagens proporcionadas pela inseminação artificial (IA), esta talvez seja a biotecnologia com maior impacto na produção equina, pois um reprodutor pode deixar centenas de descendentes ao longo de sua vida reprodutiva por meio da IA usada eficientemente. A IA em equinos é praticada mundialmente, e a maneira mais comumente usada nessa espécie é mediante o resfriamento e transporte de sêmen (Loomis, 2006).

Aparentemente, no mundo, os países que mais realizam IA com sêmen resfriado transportado são Estados Unidos, seguido pelo Brasil (Papa et al., 2005). O transporte de sêmen equino, não é, em si, um fato novo, podendo até mesmo ter sido responsável pela primeira citação na literatura, envolvendo a IA nos animais domésticos, conforme relatos em textos árabes no ano de 1322, quando um chefe determinou que coletassem sêmen de um garanhão de uma tribo rival para realizar a inseminação de uma de suas éguas (Davies-Morel, 1999).

A refrigeração do sêmen possui muitas vantagens como a diminuição de gastos inerente ao transporte e a hospedagem de animais, menor risco com acidentes e aquisição de doenças sexualmente transmissíveis e diminuição do estresse provocado pelo transporte dos animais (Brisko \& Varner, 1992).

Nos últimos anos, o uso de sêmen refrigerado ocorreu após a liberação dessa biotécnica reprodutiva pela maioria das associações de criadores, com exceção da associação do Puro Sangue Inglês (Visament et al., 1997).

Vários fatores podem interferir no resultado final da fertilização de éguas inseminadas com sêmen refrigerado, tais como: a temperatura e o tempo de armazenamento do sêmen, o tipo de container, a curva de refrigeração, o momento da inseminação, a qualidade individual do garanhão, além do tipo de diluente empregado (Pugliesi, 2009).

A necessidade do desenvolvimento de técnicas que possibilitassem um maior e melhor aproveitamento do potencial produtivo e reprodutivo de várias espécies domésticas se dá pelo crescimento e demanda existente no país (Brandão, 2008).

Uma biotecnologia utilizada é a criopreservação do sêmen, essa é uma das técnicas que vieram para facilitar e otimizar a produção. A criopreservação do sêmen proporciona inúmeras vantagens, a maior disponibilidade de espermatozoide, trazendo facilidade aos trabalhos de reprodução assistida. A otimização do uso de garanhões com comprovada superioridade genética, com a possibilidade do armazenamento do sêmen, mesmo fora do período de estação de monta e a quebra das barreiras geográficas, fazendo com que a remessa de sêmen seja enviada para qualquer parte do mundo (Barreto et al., 2008).

Portanto, as duas formas de preservação seminal (refrigerado ou congelado) podem auxiliar no manejo e no melhoramento genético dos rebanhos equinos. No entanto, para que a fertilização do oócito ocorra de forma eficiente, o sêmen colhido deve ser acondicionado e transportado de forma adequada até a propriedade onde será realizada a IA, e o óocito ovulado pela fêmea deve ser fecundado no momento adequado. A fase estral (fase folicular) na égua pode durar de 3 a 7 dias, com a ovulação ocorrendo de 24 a 48 h antes dos sinais de estro desaparecer. Esse período é dominado por um ou mais folículos pré-ovulatórios, sendo que o diâmetro folicular, na ovulação, pode variar de 30 a 70 mm (média 40 a 45 mm) (Meira, 2007).

Se a inseminação ou cobertura ocorrer depois de 12 a 14 horas da ovulação, o ovulo será considerado muito velho para ser prontamente fertilizado ou se fertilizado, falhará ao desenvolver um embrião viável (Ley, 2006). Dessa forma, o período de estro e o momento da ovulação são variáveis na espécie equina e, na maioria das vezes, para aumentar a variabilidade genética animal o sêmen utilizado é refrigerado advindo de propriedades distantes.

Assim, pode ocorrer a não disponibilidade de sêmen para IA no momento ideal ou o mesmo chegar na propriedade após o período ideal. Essa questão poderia ser resolvida se o proprietário pudesse congelar o sêmen refrigerado por tempo indeterminado para evitar a sua perda ou como estratégia na formação de um banco genético em sua propriedade. 
Assim, este projeto visa avaliar a influência de diferentes diluentes comerciais de refrigeração na motilidade, vigor, morfologia, integridade e funcionalidade da membrana plasmática de espermatozoides equinos congelados após 24 h de refrigeração à $5{ }^{\circ} \mathrm{C}$.

\section{Revisão de Literatura}

\subsection{Qualidade do Sêmen Equino}

O sêmen é o conjunto de secreções do aparelho genital masculino, caracterizando-se pela presença dos espermatozoides que são liberados no momento da ejaculação (Mies Filho, 1987).

Para que o espermatozoide tenha a capacidade de fertilizar o oócito, o mesmo deve possuir algumas propriedades como membrana plasmática íntegra, processo metabólico de produção de energia, motilidade progressiva, proteínas suficientes para que possa garantir sua sobrevivência no trato genital feminino e também permitir que ocorra a reação do acrossoma na hora de se ligar ao oócito e enzimas no acrossoma para que aconteça sua penetração (Amann \& Graham, 1993).

Um garanhão destinado a reprodução o seu sêmen precisa ter a capacidade de fertilizar um oócito, então, os espermatozoides deves possuir todas as suas partes e componentes estruturais íntegros e em perfeito funcionamento para que o seu potencial de fertilidade seja máximo (Sobreira Neto, 2008).

A capacidade de fertilização de um espermatozoide deixa de existir por problemas como a presença de membrana espermática lesionada, a função mitocondrial reduzida, motilidade espermática progressiva reduzida ou ausente bem como um acrossoma danificado. Logo, as alterações na estrutura do espermatozoide que ocorrem durante o processo de refrigeração e/ou descongelação resultam na perda da capacidade fecundante in vivo destas células (Amann \& Graham, 1993).

\subsection{Preservação do Sêmen Equino}

Os primeiros relatos que demonstraram que a diminuição da temperatura promove uma redução reversível da atividade metabólica dos espermatozoides permitindo o armazenamento destas células foram realizados por Spallazani em 1776 (Johnston, 2000).

A refrigeração do sêmen para uma posterior utilização na inseminação artificial produz um menor dano aos espermatozoides, quando comparados a congelação, proporcionando então, maiores taxas de prenhez (England; Ponzio, 1996). De acordo com Amann e Pickett (1987), para cada $10^{\circ} \mathrm{C}$ que reduz a temperatura, ocorre uma redução de 15 a $50 \%$ no metabolismo celular. Sendo assim, uma célula espermática armazenada a uma temperatura de $5^{\circ} \mathrm{C}$ possui apenas $10 \%$ do metabolismo celular ativo, elevando desta forma o tempo de sobrevivência da célula. O sêmen equino normalmente fica armazenado entre temperaturas que variam entre $4^{\circ} \mathrm{C}$ e $6^{\circ} \mathrm{C}$, pois nesta faixa de temperatura o espermatozoide mantém tanto a motilidade como a fertilidade (Moran et al., 1992). O armazenamento dos espermatozoides a $15^{\circ} \mathrm{C}$ pode diminuir danos causados à membrana espermática pelo choque do frio (Batellier et al., 2001).

O processo de refrigeração do sêmen pode ser de forma automatizada ou convencional. A automatizada é realizada em um equipamento de refrigeração, onde a temperatura decresce de forma controlada e não sofre influência da temperatura externa, já a convencional se utiliza uma caixa isotérmica, que recebe influência do meio externo onde a temperatura do ambiente e o volume da amostra influenciam a temperatura dentro da caixa. Mesmo assim, a forma convencional é a mais difundida comercialmente devido ao seu baixo custo (Valle et al., 1999).

Dentre os sistemas convencionais de refrigeração, os mais conhecidos são os Equitainer $1 \circledR$ e o Equitainer $2 ®$ que foram desenvolvidos por Douglas Hamilton et al. (1984). Entre os modelos nacionais existem uns modelos mais sofisticados, como a Botu-Box ${ }^{\circledR}$ e a Botutainer ${ }^{\circledR}$, e os modelos mais simples e populares, como o Max-Sêmen Express $®$ e o BotuFlex ${ }^{\circledR}$ (Sobreira Neto, 2008). 
A fertilidade do sêmen refrigerado é mantida no máximo por 72 horas pós-ejaculação para a maioria dos garanhões (Gunzel-Apel \& Krause 1986; Pimentel \& Carneiro 2008).

No entanto, Feldman e Nelson (1996) em estudo com cães verificaram que, o sêmen adequadamente diluído e refrigerado, os espermatozoides podem permanecer viáveis por um período de até cinco dias. Com isso, o que determina a boa qualidade do sêmen refrigerado é a qualidade do sêmen in natura, a qualidade do diluente, a forma de refrigeração e o fator individual (Squires et al., 1999).

\subsection{Sêmen in Natura}

O sêmen in natura deve ser colhido e utilizado, imediatamente, no próprio local. Tem como vantagens a economia do uso de diluidor, contudo, como desvantagem, a qualidade espermática não sendo preservada (Kenney et al., 1975).

\subsection{Semen Diluído}

O sêmen diluído tem como vantagens o tratamento antibiótico, diminuindo a contaminação bacteriana deste; diluição de fatores tóxicos presentes no plasma seminal; melhora da fertilidade do sêmen devido ao aporte de nutrientes contidos no diluidor; maior flexibilidade de inseminação, onde o sêmen depois de diluído, dependendo da situação, pode ser transportado em curtas distâncias sem necessidade de resfriamento, entre haras próximos e, se devidamente protegido dos raios solares até uma hora, sem prejuízo da fertilidade; e a possibilidade do fracionamento para maior número de éguas pela expansão do volume diluidor mais o sêmen (Squires et al., 1999).

Para sêmen equino, os diluidores utilizados são constituídos por água, tampões e substâncias não iônicas, açúcares e diferentes tipos de macromoléculas e antibióticos. De maneira geral os diluidores podem ser divididos em quatro grupos: os salinos, os com gema de ovo, os com leite e derivados e os que apresentam albumina sérica bovina (Amann; Pickett, 1987; Silva Filho, 1994).

Segundo Amann e Pickett (1987), Silva Filho (1994), um bom extensor deve proporcionar pressão osmótica compatível com o espermatozoide; equilíbrio mineral apropriado e adequada combinação de nutrientes; sistema com capacidade de neutralizar catabólitos espermáticos; substâncias com capacidade de proteger em relação as variações de temperatura, principalmente para o frio; capacidade de estabilização das membranas e sistemas enzimáticos; baixo custo; livre de microrganismos patogênicos; não oferecer toxicidade ao espermatozoide e fácil aquisição. Existe muitos diluidores que tem sido formulado ao longo de décadas com esse propósito (Kenney et al., 1975; Silva Filho et al.; 1997; Batellier et al., 1997; Papa et al., 2005).

A maioria dos extensores usados para sêmen de equino é à base de gema de ovo, leite ou seus produtos derivados (Squires et al., 1999). Os diluidores para sêmen equino comercializados no Brasil são EZ - Mixin® (CST), Max Sêmen® (Agrofarma); Botu-Sêmen ${ }^{\circledR}$ e Botu-Turbo® (Biotech Botucatu) Equimix ${ }^{\circledR}$ (Nutricell) (Raphael, 2007).

Silva Filho, Palhares e Bergmann (1987) adaptaram um diluidor à base de lactose e gema de ovo, tradicionalmente utilizado para sêmen de bovinos (Nagase; Niwa, 1964). Após a retirar o glicerol, foi utilizado como diluidor de sêmen equino, para inseminação com sêmen a fresco diluído e diluído transportado. O referido extensor (lactose-gema) vem sendo utilizado no Brasil, com bons resultados de fertilidade, equiparáveis ou superiores ao extensor de Kenney et al., (1975).

Experimentos conduzidos por Silva Filho et al. (1997), comparando o efeito do diluidor lactose-gema no transporte e na inseminação com sêmen diluído no próprio local, contra sêmen in natura nas mesmas condições transportado e utilizado no próprio local de colheita, utilizaram teste de fertilidade em 100 ciclos de 64 éguas da raça Mangalarga Marchador, e os melhores resultados foram com o sêmen diluído nas duas situações, transportado e não transportado. $\mathrm{O}$ transporte foi feito em um container desenvolvido por eles denominado MSP-1. 
Silva Filho (1994) realizou a comparação entre sêmen fresco in natura e sêmen fresco diluído, com os seguintes diluidores: 1) leite em pó-desnatadoglicose, 2) lactose-gema e 3) glicina-gema. Para isso utilizou em IA de 42 éguas mestiças da raça Bretã e da raça Campolina, por 64 ciclos, não obtendo diferenças entre os diluidores e com sêmen in natura, porém, com tendência numérica de melhores resultados para o extensor lactose-gema.

Em outro experimento conduzido em condições reais de campo, Carvalho (1992) comparou o efeito da inseminação artificial com sêmen a fresco diluído em leite desnatado-glicose, e sêmen diluído em lactose gema transportado a $15-20^{\circ} \mathrm{C}$. Para isso, realizou-se a inseminação de 79 éguas e potras da raça Mangalarga Marchador, sendo utilizada divisão igualitária entre os tratamentos, obtendo-se ao final, taxas de concepção semelhantes entre os diluidores.

\subsection{Diluição do Sêmen Equino para Refrigeração}

Os diluidores de sêmen são soluções destinadas a proteger os espermatozoides de condições desfavoráveis e prolongar sua sobrevivência durante a refrigeração e o transporte, além de apresentarem a vantagem de aumentar o volume da dose inseminante e auxiliarem na análise do sêmen (Pickett \& Shiner, 1994; Ball, 1998b; Darenius, 1998).

Para avaliar a qualidade do meio diluidor, devem ser aferidas a pressão osmótica e o pH, e estes devem apresentar valores entre 300 a 350 mOsm e 7,0 a 7,2, respectivamente (Darenius, 1998). Uma característica importante dos diluidores utilizados na preservação do sêmen refrigerado é sua capacidade de estabilizar as membranas espermáticas durante a fase de transição, momento no qual ocorrem as maiores lesões celulares. Assim, para minimizar os danos causados pelo choque térmico, uma variedade de substâncias pode ser adicionada ao meio diluidor (Kenney et al., 1975).

Os diluentes utilizados para preservação do sêmen equino refrigerado, geralmente, possuem gema de ovo e/ou leite como um dos componentes (Heitland et al., 1995). A gema de ovo proporciona proteção aos espermatozoides contra o choque térmico e essa ação protetora é atribuída às lipoproteínas de baixa densidade (Amann e Graham, 1993), que permanecem firmemente ligadas aos espermatozoides, em especial a lipoproteína (Foulkes, 1977).

A gema de ovo também estabiliza a membrana espermática por meio da neutralização dos componentes deletérios existentes no plasma seminal (Aurich, 2005). Porém, contém progesterona na gema de ovo, o que poderia levar a uma indução capacitação espermática precoce, ocasionando redução da fertilidade, pois, conforme demonstrado por Cheng et al. (1998), a ligação da progesterona exógena marcada ao receptor localizado na membrana plasmática do espermatozóide equino parece ser um importante passo na indução da reação do acrossomo.

Embora não se conheça o exato mecanismo de proteção do leite contra o choque térmico, provavelmente as proteínas do leite agem de modo similar às lipoproteínas da gema de ovo, ou seja, estabilizando as membranas (Amann e Graham, 1993).

Batellier et al. (2001) relatam que a proteção conferida pelos componentes do leite estaria relacionada aos seus efeitos antioxidantes. De acordo com Batellier et al. (1997), o leite é um fluído biológico com uma complexa composição, mais de 100.000 moléculas, e algumas como a $\beta$-lactoglobulina são benéficas, enquanto outras, como a $\alpha$-lactoalbumina, são prejudiciais à sobrevivência dos espermatozoides.

O uso do leite em pó desnatado como um dos componentes do meio diluidor foi primeiramente relatado por Kenney et al. (1975), que obtiveram uma taxa de prenhes de 58\% para as éguas inseminadas. Ferreira (1993) comparou dois diluentes, um contendo gema de ovo e outro à base de leite, para a preservação do sêmen asinino sob refrigeração ativa entre 4 e $6^{\circ} \mathrm{C}$. A partir de 24 horas, o autor observou maior motilidade espermática total, progressiva e vigor $(p>0,05)$ para o sêmen diluído em meio à base de gema de ovo.

De acordo com Batellier et al., (1997), Pagistrini et al., (1992), Batellier et al., (2001), a utilização de diluentes contendo leite é mais adequada quando as amostras de sêmen equino são armazenadas em torno de $4^{\circ} \mathrm{C}$. Já na refrigeração a 
$15^{\circ} \mathrm{C}$, as amostras de sêmen são favorecidas quando se utiliza um diluente sem leite (Magistrini et al., 1992; Batellier et al., 2001).

No entanto, no estudo realizado por Farrás et al (2008), onde foram comparados diluentes à base de leite desnatado (Botu-Semen ${ }^{\circledR}$ e Botu-Turbo®) e outro contendo apenas frações purificadas do leite (INRA 96®), observou-se que todos os diluentes podem ser utilizados sem prejuízos para a motilidade e viabilidade espermáticas, tanto a temperaturas em torno de $5^{\circ} \mathrm{C}$ como de $15^{\circ} \mathrm{C}$.

Bruemmert et al. (2002) e Squires et al. (1999) descreveram que a adição de antioxidantes aos diluentes pode ser benéfica para a preservação da motilidade e da integridade da membrana espermática. Entretanto, Ball et al. (2001) não relataram efeito benéfico de diferentes substâncias antioxidantes sobre a preservação da motilidade durante 72 horas de estocagem.

Goulart et al. (2004), tentando minimizar os efeitos provocados pelo estresse térmico causado pela refrigeração do sêmen equino, adicionaram a pentoxifilina ao ejaculado diluído e refrigerado a $5^{\circ} \mathrm{C}$, in vitro. Esta substância, por sua vez, melhorou a maioria dos parâmetros espermáticos relacionados à motilidade, provavelmente, devido ao aumento da concentração intracelular de nucleotídeos cíclicos, em especial da adenina monofosfato cíclica (AMPc) e da guanosina monofosfato cíclica (GMPc). A utilização de antibióticos nos meios diluentes se dá afim de minimizar o crescimento de bactérias durante o período de armazenamento do sêmen até o momento do uso na inseminação (Darenius, 1998).

A superfície do pênis e do prepúcio do garanhão é habitada por uma grande variedade de bactérias comensais e por algumas espécies patogênicas (Pseudômonas aeruginosa, Klebsiella pneumoniae e Taylorella equigenitalis) que podem promover endometrites na fêmea equina e redução na qualidade seminal, ocasionando subfertilidade dos garanhões (Pickett et al., 1999).

Vários agentes antimicrobianos têm sido utilizados no sêmen equino: amicacina, amoxicilina, ampicilina, eritromicina, gentamicina, kanamicina, lincomicina, ácido nalidíxico, polimixina B, estreptomicina, ticarcilina, penicilina $\mathrm{G}$ e ceftiofur. Back et al. (1975) utilizaram um ejaculado de sete garanhões para avaliar o efeito de oito antibióticos (eritromicina, sulfato de gentamicina, ácido nalidíxico, sulfato de kanamicina, lincomicina, penicilina G sódica, polimixina B e sulfato de estreptomicina) sobre a motilidade progressiva espermática. Estes autores verificaram que o sulfato de estreptomicina teve efeito deletério no sêmen fresco quando adicionado em altas concentrações (1.500, 2.000 e $2.500 \mu \mathrm{g} / \mathrm{mL})$, ao passo que os demais tiveram efeito semelhante na manutenção da motilidade, tanto no sêmen fresco como no resfriado.

Hoyumpa et al. (1992) e Varner et al. (1992), em estudos sobre os efeitos de antibióticos na redução do número de colônias de diversos tipos de bactérias (aeróbicas obrigatórias, anaeróbicas facultativas e anaeróbicas), evidenciaram que a combinação de penicilina $\mathrm{G}$ potássica e amicacina teve efeito melhor que o uso isolado da penicilina e da amicacina no sêmen resfriado a $5^{\circ} \mathrm{C}$.

\subsection{Criopreservação}

A criopreservação do sêmen equino é uma importante biotecnologia usada no melhoramento genético da espécie, pela otimização e maximização do uso de bons reprodutores. Um ponto negativo é que os índices de fertilidade obtidos com o sêmen congelados de equinos ainda são muito abaixo dos obtidos com sêmen congelado de bovinos (Fürst et al, 2005).

A observação da diminuição em relação a taxa de fertilidade após o processo de congelamento e descongelamento está relacionada aos danos causados ao funcionamento e às estruturas das membranas dos espermatozoides (Parks \& Graham, 1992). Por isso, diversos fatores devem sempre ser analisados no congelamento de sêmen de equinos, por exemplo: exposição dos espermatozoides ao processo de refrigeração, danos causados pelos cristais de gelo e mudanças intracelulares pela desidratação (Amann \& Pickett, 1987). 
A refrigeração consiste em uma das etapas para criopreservação, quando efetuada de modo inadequado, causa choque térmico que induz a ocorrência de danos parcialmente irreversíveis ao espermatozoide, caracterizados por padrões anormais de movimento (circular ou retrógado), perda acentuada da motilidade, lesões acrossomais, danos à membrana plasmática, atividade metabólica reduzida e perda dos componentes intracelulares. Muitos desses defeitos são por meio de alterações da membrana plasmática à medida que os espermatozoides evoluem nas transições de fase, de estado líquido cristalino para o estado de gel e durante a refrigeração (Graham, 1996).

Antes da criopreservação, da fase do congelamento o sêmen equino deve ser refrigerado da temperatura corpórea à temperatura ambiente $\left(37\right.$ a $\left.20^{\circ} \mathrm{C}\right)$, sem que ocorra danos aos espermatozoides.

O sêmen precisa ser diluído em meio adequado. O momento de maior impacto é na queda temperatura de $20^{\circ} \mathrm{C}$ até $5^{\circ} \mathrm{C}$, onde ocorre um estresse inicial (Squires et al., 1999), por conta da mudança de fase da membrana plasmática, e essa alteração de fase dificulta a permeabilidade dos crioprotetores no meio (Graham, 1996; Medeiros, 2002).

Durante o processo de congelamento, a amostra de espermatozoides atinge temperaturas abaixo do ponto de congelamento do meio (super resfriamento), antes que ocorra a formação de cristais. Quando inicia o processo de formação dos cristais de gelo, a membrana pode ser lesionada sendo deletério para o espermatozoide, mas curvas de congelamento adequadas podem minimizar esse efeito (Squires et al., 1999).

A água extracelular congela quando o processo de congelamento é lento, e consequentemente ocorre à concentração de soluto, colocando a célula, momentaneamente, em um meio hipertônico e permitindo a perda rápida da água, levando à desidratação celular. Por outro lado, quando o congelamento acontece rapidamente, não acontece perda de água, permitindo com isso, a formação de cristais de gelo intracelular (Mazur, 1985).

Sob a temperatura de $5^{\circ} \mathrm{C}$, a água intra e extracelular permanece super refrigerada e não há cristaliza. Porém, quando atingem temperaturas de $-5 \mathrm{e}-10^{\circ} \mathrm{C}$ os cristais começam a se formar, logo, a curva de congelamento deve ser lenta para que evite o congelamento da água intracelular, e rápida o suficiente para evitar o contato da célula desidratada com o meio hiperósmico. A acentuada perda de água permite a desnaturação das macromoléculas e encolhimento em excesso da célula permitindo o colapso da membrana plasmática (Medeiros, 2002).

A perda de água e desidratação celular são eventos desejáveis, porque reduzem a probabilidade da formação de cristais de gelo dentro da célula, o que ocasiona danos às estruturas internas e/ou à membrana plasmática (Squires et al.,1999).

\subsubsection{Componentes dos Diluentes}

Como forma de otimizar a qualidade do seminal e protegê-los, deve-se acrescentar diluentes (Zimmermann, 2007). Por conseguinte, esses diluentes são adicionados com a intenção de proteger os espermatozoides dos efeitos críticos do congelamento (Aidar, 2013). Assim, são adicionados crioprotetores e macromoléculas que terão função de proteger a membrana plasmática das possíveis injúrias (Aidar, 2013); ainda, deve-se adicionar fonte de energia para o metabolismo espermático e meio tampão para a manutenção do pH (Parks \& Graham, 1992; Aidar, 2013).

O diluidor para que seja considerado ideal deve assegurar: compatibilidade da pressão osmótica com a dos espermatozoides; apropriado equilíbrio mineral e adequada combinação de nutrientes; capacidade de neutralização de catabólitos espermáticos; substâncias com capacidade de proteger sob alterações de temperatura, principalmente para o frio; capacidade de estabilização de membranas e sistema enzimático; ambiente livre de microorganismos patogênicos; baixo custo; não oferecer toxicidade ao espermatozoide; baixa ou sem irritabilidade ao sistema genital e de fácil aquisição (Amann \& Pickett, 1987; Silva Filho, 1994; Aidar, 2013; Canisso et al., 2008).

Faz-se necessário ressaltar que, a composição adequada para um diluidor seminal não depende apenas de uma adequada concentração de crioprotetores, tanto intra como extracelulares, mas de uma combinação adequada de todas as 
substâncias que são utilizadas, levando-se em consideração a fonte de energia para os espermatozoides, as substâncias não iônicas, o tipo de macromoléculas e a concentração e o tipo ideal de crioprotetor (Snoeck et al, 2007).

\subsubsection{Crioprotetores}

Os crioprotetores são substâncias capazes de promover a sobrevivência dos espermatozoides durante a congelação e descongelação, apesar de seu mecanismo de ação não estar bem elucidado (Fürst, 2006).

Entretanto, Mazur (1970), Meryman et al. (1977) e Aidar (2013), contestaram tais argumentos, quando relatam que o mecanismo de ação dos crioprotetores baseiam-se na diminuição do ponto de solidificação da solução, proporcionando um tempo maior para a desidratação das células, assim reduzindo a criação de cristais de gelo intracelulares.

Embora os crioprotetores sejam essenciais ao processo de congelação dos espermatozoides, eles podem apresentar efeitos tóxicos e diminuir taxas de fertilidade quando em concentrações elevadas (De Vita, 2006). Devido aos efeitos tóxicos dos crioprotetores, eles não garantem a sobrevivência de $100 \%$ dos espermatozoides, dependendo da concentração utilizada do crioprotetor no meio diluidor (Fahy, 1986; Fürst, 2006).

Segundo Zimmermann (2007), a adição de crioprotetores em múltiplas etapas, associados ao resfriamento da amostra de forma lenta antes do congelamento, é o tratamento mais eficaz para preservar a viabilidade das células espermáticas de equinos.

Keith (1998) classificou os crioprotetores em dois grupos: não penetrantes (extracelulares) e penetrantes (intracelulares). Os crioprotetores intracelulares atuam afim de reduzir o ponto crioscópico intracelular permitindo que uma maior quantidade de água permaneça no estado líquido, quando são submetidas a temperaturas baixas, a redução da concentração intracelular de solutos, criando um ambiente menos deletério às células espermáticas durante o processo de congelamento (Watson, 1995; Aidar, 2013).

Alguns exemplos de crioprotetores são: dimetil sulfóxido, glicerol, etileno glicol e propileno glicol, que podem ser utilizados individualmente ou em associação (Alvarenga, 2002; Aidar, 2013). Os crioprotetores extra celulares atuam como solutos ou colóides, não sendo úteis como solventes; alguns exemplos são: açúcares (lactose, frutose, rafiose ou trealose) e polímeros sintéticos (metil celulose) (Graham, 1996; Aidar, 2013).

\subsection{Protocolos de Congelamento}

Para que o sêmen seja centrifugado, primeiro, deve ser diluído. A centrifugação tem com finalidade a remoção de grande parte do plasma seminal, e concentração do ejaculado para posteriormente haja a adição do diluente de congelamento (Ashwoodsmith, 1987). Apesar da necessidade, a centrifugação não é um processo inócuo para o espermatozoide, e pode ser considerado um ponto crítico, por existir o risco da indução de peroxidação dos lipídeos da membrana (Parinaud et al., 1997).

A porção livre de gel do ejaculado é diluída em meio apropriado até obter concentração de aproximadamente, 50x106 espermatozoides $/ \mathrm{mL}$ para a centrifugação. O diluente é pré-aquecido a temperatura de $37^{\circ} \mathrm{C}$ e o sêmen diluído é situado em tubos de 15 ou $50 \mathrm{ml}$ e centrifugado por 10 a 15 minutos a 400 - 600 G. Os diluentes normalmente são usados para o processo de centrifugação: Kenney, citrato-EDTA, glicose-EDTA e lactose-EDTA, glicose-leite desnatado, leite desnatado UHT, INRA, entre vários0 outros (Martim, et al., 1979; Mckinnon, 1996; Vidament, 2005).

Após a centrifugação das amostras, o sobrenadante aspirado e desprezado, e a seguir realiza a ressuspensão do "pellet", constituído de espermatozoides, no meio diluente de congelamento, na proporção de 1:1, ou aproximada.

A diluição inicial é feita para que o cálculo da concentração seja realizado e assim reajustar o volume para obtenção da concentração espermática por mililitro desejado. É considerada aceitável uma redução de $10 \%$ da motilidade espermática pela centrifugação é (Mckinnon, 1996). 
A concentrações finais em média variam de 25 a 400 milhões de espermatozoides/mL (Jasko, 1994; Vidament et al., 1997). Porém, são observados os melhores resultados com concentração de 100 ou 200 milhões de espermatozoides/mL (Nascimento, 2006).

Em seguida é feito o envase do sêmen diluído, em palhetas plásticas com capacidade de armazenamento de $0,5 \mathrm{~mL}$ ou 0,25 mL objetivando a obtenção de um congelamento mais uniforme das amostras (Vidament et al., 1997).

Logo em seguida inicia-se a refrigeração para a estabilização da membrana plasmática. As taxas de resfriamento podem ser divididas em de três categorias: lentas (menor que $\left.0,33^{\circ} \mathrm{C} / \mathrm{min}\right)$; médias $\left(0,33^{\circ} \mathrm{C} / \mathrm{min}\right.$ a $\left.1,0^{\circ} \mathrm{C} / \mathrm{min}\right)$ e rápidas $(\mathrm{maior}$ que $1,0^{\circ} \mathrm{C} / \mathrm{min}$ ). A de maior utilização é a refrigeração média, e este processo é realizado por volta de $35^{\circ} \mathrm{C}$, até acontecer estabilização da temperatura em $5^{\circ} \mathrm{C}$ (Douglas-Hamilton et al., 1984).

Após, vem o processo de criopreservação que é o congelamento do sêmen. Não há um protocolo pré determinando para alcançar a curva ideal, porque esta depende de muitos fatores, por exemplo, à composição do meio diluidor, a adição do crioprotetor, a concentração do crioprotetor e taxas de resfriamento (Heitland et al., 1996).

Grande parte dos protocolos utilizados atualmente disponíveis para o congelamento é utilizada uma curva de congelamento rápida de $-60^{\circ} \mathrm{C} / \mathrm{min}$., sendo alcabçada pela exposição das palhetas horizontalmente, $6 \mathrm{~cm}$ acima do vapor de nitrogênio por 15 a 20minutos (Amann \& Pickett, 1987).

\subsection{Descongelação}

A variação da curva de descongelamento acontece de acordo com o tipo de envasamento e tempo de exposição da amostra a uma determinada temperatura (Pickett \& Amann, 1993). Quando a curva de congelamento é muito rápida, não há tempo suficiente para que a desidratação adequada ocorra, resultando na formação de grandes cristais de gelo que são formadas no meio intracelular. Então, para descongelar a velocidade também necessita ser rápida, para que não aconteça a recristalização (fusão de cristais de gelo) e, a ocorrência de lesão celular. Da mesma maneira o congelamento lento requer um descongelamento lento. Sendo assim, a desidratação celular é maior e há necessidade de um tempo maior para que aconteça a reidratação espermática, para que a célula não perca a sua viabilidade morfofuncional (Mazur, 1985).

Holt (2000) sugere que para fazer o descongelamento de amostras de sêmen testando com diferentes curvas de aquecimento é recomendada a utilização de temperaturas relativamente altas, banho-maria entre $60^{\circ} \mathrm{C}$ e $70^{\circ} \mathrm{C}$ por 7 segundos. Em estudos já realizados onde o foco era a avaliação de diferentes tipos de envasamentos e a influência no descongelamento, foi concluído que, para o envasamento em palhetas com capacidade para um volume de 0,5 e de $0,25 \mathrm{~mL}$ e macrotubos de 4 $\mathrm{mL}$, a temperatura que houve melhores resultados foi com parâmetros espermáticos como motilidade progressiva, em análises computadorizadas, foi $65^{\circ} \mathrm{C}$ por 6 segundos (Dell’Aqua Junior \& Papa, 2001).

\subsection{Técnicas de Avaliação do Sêmen Descongelado}

Os critérios estabelecidos para que seja utilizado o sêmen descongelado na IA (Inseminação Artificial) têm sido preconizados como sendo no mínimo $30 \%$ de motilidade total logo após a finalização do descongelamento (Cristanelli et al., 1984; Love et al., 1989).

Porém, só a avaliação da motilidade espermática não informa adequadamente a capacidade de fecundação do sêmen (Graham et al., 1996). No Brasil, o CBRA (2003) estabeleceu como parâmetros para condenação do sêmen criopreservado valores inferiores a $30 \%$ de motilidade total, vigor menor que 3 e acima de $40 \%$ de espermatozoides com defeitos. Por conta dos parâmetros convencionais das características espermáticas mostrarem-se baixas, ou nenhuma correlação com a fertilidade, outras técnicas vem sendo desenvolvidas com o objetivo da avaliação da melhor capacidade fecundante do sêmen nas diferentes espécies (Jeyendran et al., 1984; Smith \& Murray, 1997; Vazquez, 1997; Melo, 1999). 
Segundo Furst (2006), entre os testes com o objetivo dizer com maior acurácia a capacidade de fertilização do gameta masculino pode se citar as técnicas que usam corantes específicos, microscopia eletrônica ou avaliação do comportamento do sêmen mediante soluções hiposmóticas.

a) Coloração supravital: é conhecida também como coloração de vivos e mortos, consiste na utilização de corantes derivados da fluoresceína, que podem ou não estar combinados com outros corantes de fundo. A ação desses corantes depende da integridade estrutural da membrana plasmática da cabeça do espermatozoide, permitindo ou não a penetração no compartimento nuclear do mesmo (Garner et al., 1986). Os corantes usados para esta finalidade são a eosina e a nigrosina. A eosina é um corante supravital que não penetra em células quando estas possuem a membrana plasmática intacta, mas, quando lesadas, a estrutura é coradas em rosa. A nigrosina é responsável pelo contraste mais escuro de fundo da lâmina, o qual permite a visualização dos espermatozoides não corados. Por isso, este teste tem sido recomendado como uma avaliação adicional àquelas que são rotineiras (Brito, 2007).

b) Teste hiposmótico (Host): é o método utilizado para se verificar a integridade funcional da membrana da célula espermática em diversas espécies (Fürst, 2006). Este teste é baseado na capacidade que o espermatozoide possui de reagir quando exposto a soluções hiposmóticas. Isso se deve ao fato de que nessas condições ocorre o influxo de água para dentro da célula, para que um equilíbrio osmótico seja estabelecido entre o meio extra e intracelular, provocando o aumento de volume na célula e posterior dobramento da cauda (Jeyendran et al., 1992). A reatividade da membrana espermática ao meio hiposmótico está provavelmente relacionada com a presença de um mecanismo iônico ativo na membrana celular, envolvendo o sistema de bomba de $\mathrm{Na}+$ / $\mathrm{K}+$ (Darnnel et al, 1986).

c) Teste termorresistência (TTR): consiste na incubação do sêmen a temperatura de $36^{\circ} \mathrm{C}$ por um período de 30 minutos à duas horas. Neste teste são analisados motilidade e o vigor espermático ao longo desse tempo. Vários fatores vão influenciar no resultado deste teste, dentre eles: efeito do ejaculado (Pinto et al., 1978), método de congelamento (Pickett et al., 1961) e efeitos do tempo incubação (Jondet, 1980).

A congelação de sêmen traz vários benefícios ao sistema de produção dos equinos, facilitando o armazenamento por período indeterminado e a comercialização deste material genético, controlando doenças sexualmente transmissíveis e, principalmente, acelerando o ganho genético. Em equinos, essa técnica tem sido aperfeiçoada constantemente, com a utilização de diferentes diluentes e crioprotetores, que apresentam resultados cada vez mais satisfatórios.

Outra biotecnologia reprodutiva muito utilizada no campo é a refrigeração do sêmen para posterior inseminação artificial, pois permite a diminuição de gastos inerente ao transporte e a hospedagem de reprodutores, menor risco com acidentes e aquisição de doenças sexualmente transmissíveis, e diminuição do estresse provocado pelo transporte dos animais.

No entanto, tanto a refrigeração quanto o congelamento do sêmen necessitam de cuidados em sua operacionalização, pois as células espermáticas são sensíveis, e qualquer choque de temperatura ou erro na manipulação podem comprometer todo o produto (sêmen) e afetar diretamente os índices reprodutivos.

O objetivo com este estudo é trazer de uma forma simplificada a técnica de criopreservação do sêmen de equinos, podendo assim agregar conhecimento aos profissionais e estudantes de medicina veterinária, e diminuindo erros que comprometem a qualidade espermática. 


\section{Materiais e Métodos}

Os métodos qualitativos são aqueles nos quais é importante a interpretação por parte do pesquisador com suas opiniões sobre o fenômeno em estudo (Pereira A.S. et al., 2018). A pesquisa descrita é de caráter qualitativo, com objetivo de interpretação por parte dos leitores, buscando executar a técnica conforme descrita.

Para o processamento de sêmen equino, seja para refrigeração e/ou congelação serão usados os seguintes materiais e equipamentos.

\subsection{Coleta}

Ficha de identificação do animal e produtor para preenchimento.

Vagina artificial modelo para equinos (Figura 1);

Mucosa plástica para vagina;

Aquecedor de água;

Funil para colocar a água aquecida na vagina artificial;

Tubo/copo coletor protegido da luminosidade;

Filtro para coleta;

Manequim ou fêmea em estro (contida).

Figura 1. Vagina Artificial modelo Botupharma.

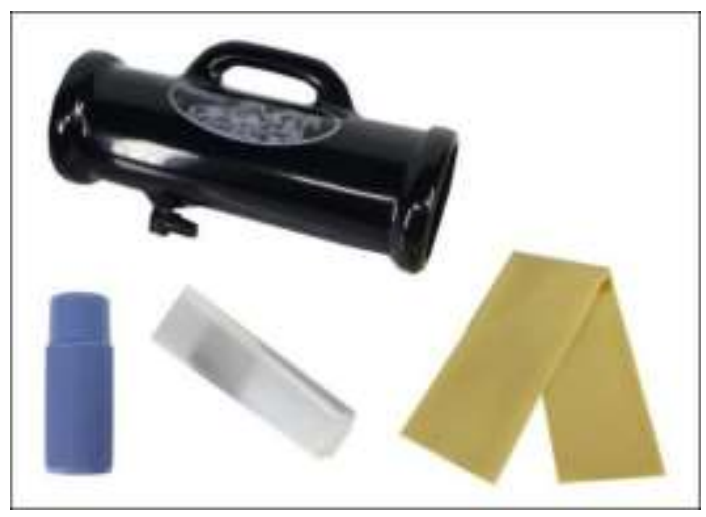

Fonte: www.botupharma.com.br/.

Vagina artificial é composta por parte plástica (externa), mucosa de látex é o que a compõe por dentro, essa mucosa é revestida por uma mucosa plástica para que haja ejaculação na mesma e os espermatozoides sejam carreados para o tudo coletor.

\subsection{Análise imediata da amostra coletada}

Lamínula (A);

Lâmina (B);

Câmara de Neubauer (C);

Ponteiras (amarelas 0-200uL e azuis 200-1000uL) (D);

Microtubos de plástico (2 mL) (E);

Tubo plástico $(25 \mathrm{~mL})(\mathrm{F})$;

Formol salino-tamponado $(\mathrm{G})$; 
Mesa aquecedora à $37^{\circ} \mathrm{C}(\mathrm{H})$;

Kit de micropipetas (I);

Microscópio (J).

Figura 2. Materiais usados na análise imediata da amostra coletada.

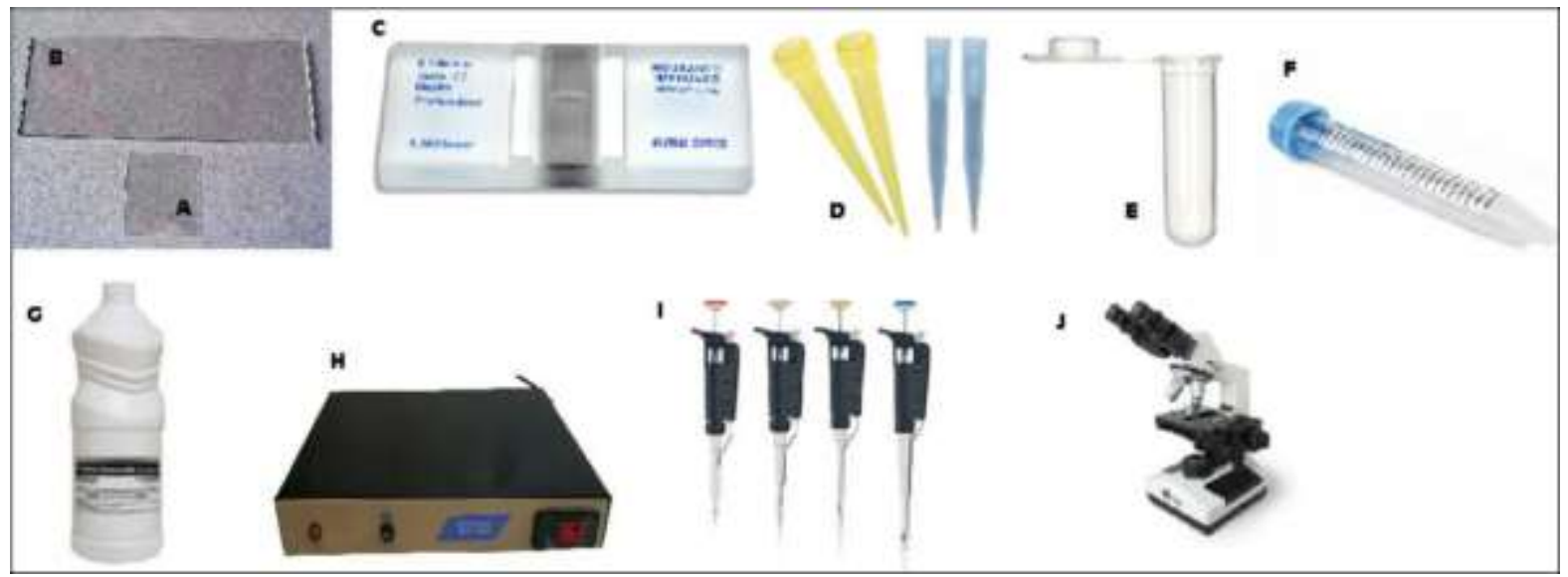

Fonte: https://www.hexis.com.br/produtos/.

Os matérias utilizados na análise imediata do sêmen coletada (Figura 2) são: Lâmina e lamínula (B e A) para que a viabilidade da amostra seja observado por meio de microscópio (J), essas amostras são condicionadas para centrifugação por tubos plásticos (F), os microtubos plásticos de 2,5 mL são usados para armazenamento de amostras para análise morfológica, essas amostras seminais são coletadas por pipetas (I), usando ponteiras (D) e depositadas nos microtubos com solução formol salino- tamponado $(\mathrm{G})$. A placa aquecedora $(\mathrm{H})$ é utilizada para que não haja choque térmicos nas amostras enquanto as mesmas são manipuladas. A câmara de Neubauer (C) é utilizada para mensuração da concentração espermática.

\subsection{Refrigeração e Congelação}

Geladeira (equipamento);

Caixa BotuFLEX® (Botupharma);

Gelos recicláveis;

Banho Maria (equipamento);

Caixa térmica para resfriação e congelação;

Termômetro digital;

Rampa de congelação;

Palhetas de envase de sêmen $(0,5 \mathrm{~mL})$;

Esferas de lacrar palhetas;

Centrifuga para tubos de $25 \mathrm{~mL}$;

Diluentes comerciais para resfriação: BotuSÊMEN®, BotuSÊMEN Special®, BotuTURBO®, BotuGOLD®

(Botupharma), ou DiVita® (BioDux);

Diluente para congelação: BotuCRIO® (Botupharma);

Pinça;

Botijão Criogênico (raques e canecas);

Nitrogênio líquido; 
Régua para medir nitrogênio;

Equipamento de proteção individual (EPI), posição de quem está contendo o animal deve ser do mesmo lado do médico veterinário que está realizando a coleta.

\subsection{Colheita do Sêmen}

Identificação do animal e do proprietário;

Exame do animal (anamnese, exame clínico geral e exame clínico específico do aparelho reprodutor);

A realização da colheita do sêmen é efetuada com o auxílio de uma vagina artificial, sendo que o reprodutor deve ter um condicionamento prévio para que este monte em uma égua em cio ou em manequim; (Figura 3).

A vagina artificial (Botupharma®) é composta de um tubo rígido, uma mucosa de látex e um copo coletor que deve ser protegido de luz e alterações de temperatura;

Ela deve ser preenchida com água quente e a temperatura deve permanecer em torno de $42-45^{\circ} \mathrm{C}$ para colheita; $\mathrm{O}$ animal condicionado deve saltar sobre o manequim e o pênis desviado/introduzido na vagina artificial;

A ejaculação é constatada a partir da observação das seguintes características: movimento da cauda para cima e para baixo, contração dos músculos perianais, sapateamento e fluxo pulsátil uretral da ejaculação;

Coletas não devem ser realizadas todos os dias, a coleta dia sim, dia não pois o resultado das amostras são bem próximas a coletas realizadas uma vez por semana.

Nota: A resposta do diluente pode alterar de garanhão para garanhão por isso existe o kit test desenvolvido pela Botpharma para realizar o teste vendo qual diluente é o melhor para o garanhão coletado.

Figura 3. Coleta de sêmen equino com vagina artificial usando manequim

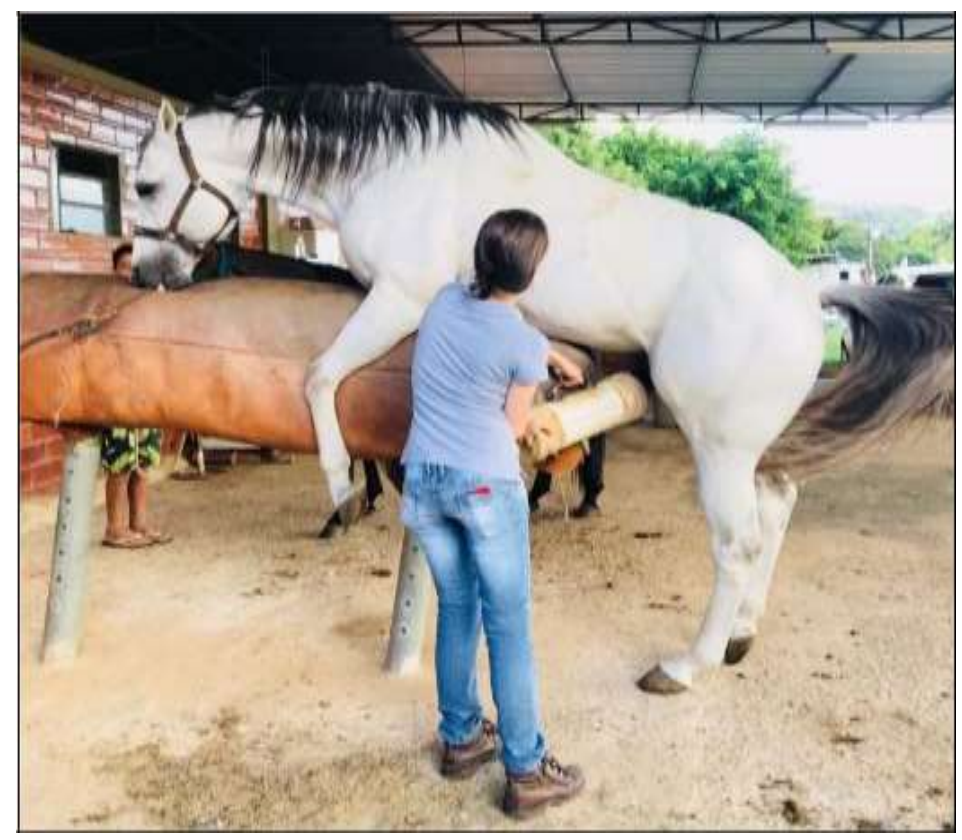

Fonte: Acervo pessoal.

A coleta de sêmen (Figura 3) deve ser realizada em um animal devidamente a realização da monta no manequim, esse animal deve ser levado ao lugar que contenha o manequim, em um ambiente tranquilo para que a coleta seja realizada com sucesso, a coleta é feita por meio da vagina artificial. 


\subsection{Exames do Sêmen Fresco}

\subsubsection{Características Macroscópicas}

Após a colheita do sêmen deve-se analisar as características macroscópicas e microscópicas:

o Volume: de 20 a $100 \mathrm{~mL}$;

o Cor: de branco acinzentado até um branco leitoso;

o Densidade/aspecto: de aquoso até leitoso. Está diretamente relacionado com a concentração espermática, ou seja, quanto mais denso maior a concentração;

o Odor: "sui-generis".

\subsubsection{Características Microscópicas}

o Motilidade espermática: coloca-se $10 \mu \mathrm{L}$ de sêmen entre lâmina e lamínula aquecidas em placa aquecedora a $37{ }^{\circ} \mathrm{C}$ e realiza-se a visualização em microscópio (aumento de 200 vezes). A motilidade espermática é analisada de acordo com uma escala de porcentagem que varia de 0 a 100\% (Motilidade Total = MT, porcentagem de células móveis). Se a amostra estiver muito concentrada deve-se realizar uma diluição em meio diluidor para resfriamento, como por exemplo a diluição de $1: 1$, motilidade ideal $\geq 70 \%$.

○ Vigor espermático: juntamente com a motilidade espermática avalia-se o vigor espermático. Em uma escala de 0 a 5 verifica-se a velocidade com que os espermatozoides se deslocam.

- Concentração espermática: coloca-se uma alíquota de $20 \mu \mathrm{l}$ de sêmen em um microtubo de $2 \mathrm{~mL}$ contendo $1 \mathrm{~mL}$ de água destilada. Após homogeneização, monta-se uma Câmara de Neubauer, conta-se todos os espermatozoides nos dois lados da câmara (retículos) e calcula-se a média aritmética (n). A variação entre cada um dos lados da câmara (retículos) não pode ser mais que $10 \%$ ).

o Morfologia espermática: coloca-se uma gota de sêmen em uma lâmina previamente aquecida à $37{ }^{\circ} \mathrm{C}$ e realiza-se um esfregaço (Figura 2). Em seguida, fixa-se o esfregaço em metanol e cora a lâmina com corantes eosina-nigrosina. Conta-se imediatamente, em microscópio óptico, 200 células espermáticas, percorrendo a lâmina de forma homogênea e classificando os espermatozoides conforme suas patologias, obtendo no final as porcentagens de espermatozoides normais e de cada patologia.

o $\quad$ Após a contagem dos espermatozoides (n), utiliza-se a fórmula:

Concentração espermática $=$

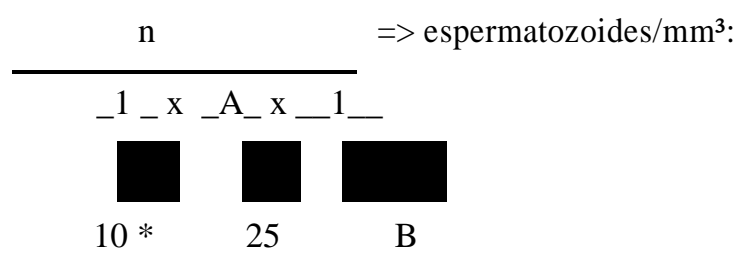

*Altura da câmara de Neubauer que está sendo usada.

Sendo:

n: número de espermatozoides contados nos dois retículos (Figura 2);

ㅁ 1/20: altura da câmara $(0,2 \mathrm{~mm})$;

$\square \quad$ A: número de quadrados grandes contados;

$\square \quad$ B: fator de diluição. 
Figura 4. Visualização de um retículo de um dos dois lados da câmara de Neubauer, com cinco quadrados grandes destacados em vermelho.
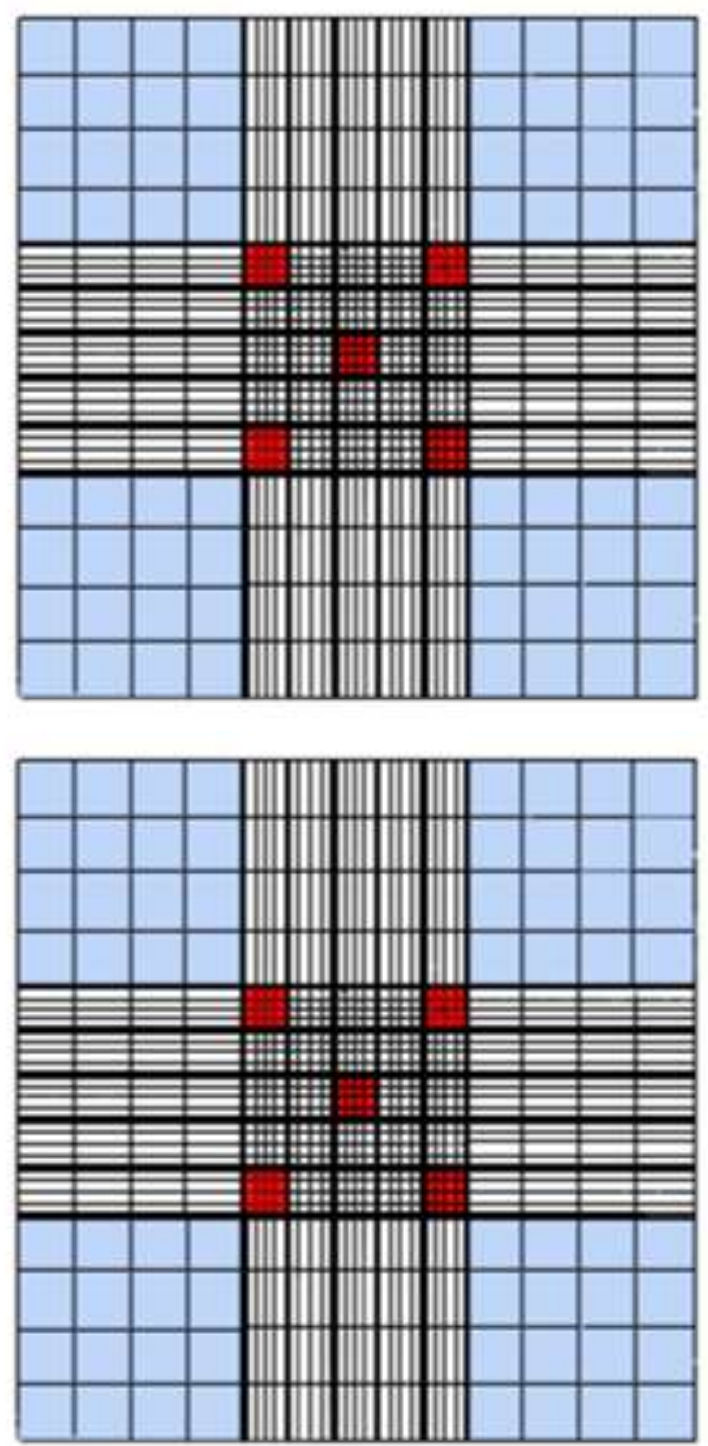

Fonte: www.patclinvetuff.blogspot.com.

Ex.: de um total de vinte cinco quadrados grandes em um lado da câmara (retículo), foram escolhidos cinco e contados 104 espermatozoides. No outro lado, foram contados 102 espermatozoides (variação entre os lados menor que 10\%). Assim, o valor de “n” será 103 espermatozoides (média aritmética). Se foi utilizado uma diluição de 1:20, o cálculo ficará:

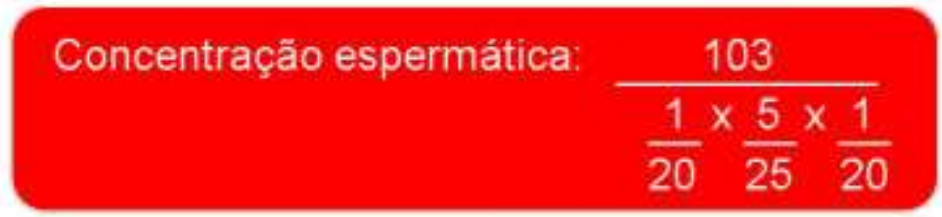

Concentração espermática: 206 x $10^{3}$ espermatozoides $/ \mathrm{mm}^{3}$. Para apresentar o resultado em mL deve-se multiplicar o valor encontrado por $1.000\left(10^{3}\right)$. Assim, a concentração espermática foi de 206 x $10^{6}$ espermatozoides $/ \mathrm{mL}$. 
Figura 5. Demonstração da técnica do esfregaço corado em lâmina.

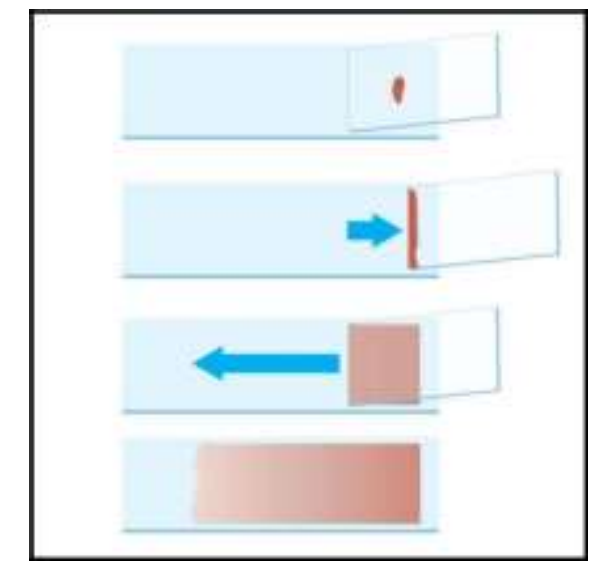

Fonte: www. kasvi.com.br/esfregaco-de-sangue-hematologia/

\subsection{Métodos de Diluição e Refrigeração}

\subsubsection{Diluição}

$\square \quad$ Diluir com diluente comercial a base de leite, contendo antibióticos, sendo de preferência uma associação de Amicacina e Penicilina cristalina, ou pode ser utilizada a gentamicina.

$\square \quad$ Diluir o sêmen fresco com 2 partes de meio (2 meio:1 sêmen).

- Cada dose inseminante deve conter no mínimo de 250 a 500 milhões de espermatozoides viáveis. Em cada dose a concentração deve estar entre 20 e 50 de milhões de espermatozoides $/ \mathrm{mL}$.

$\square \quad$ Após a separação das doses, cada uma delas deve ser envasada em um recipiente para transporte de sêmen refrigerado com a menor quantidade de ar possível.

\subsubsection{Refrigeração}

- Colocar a amostra dentro de recipiente especializado (BotuFLEX ${ }^{\circledR}$ - Botupharma) para mantê-la a temperatura de 5 ${ }^{\circ} \mathrm{C}$ (Figura 6).

OBS.: o BotuFLEX ${ }^{\circledR}$ deve conter dois gelos recicláveis que foram mantidos pelo menos 24 horas a $-10^{\circ} \mathrm{C}$ ); segundo o fabricante, as amostras ficam viáveis por 48 horas mantendo $5{ }^{\circ} \mathrm{C}$.

Figura 6 Caixa de transporte de sêmen refrigerado.

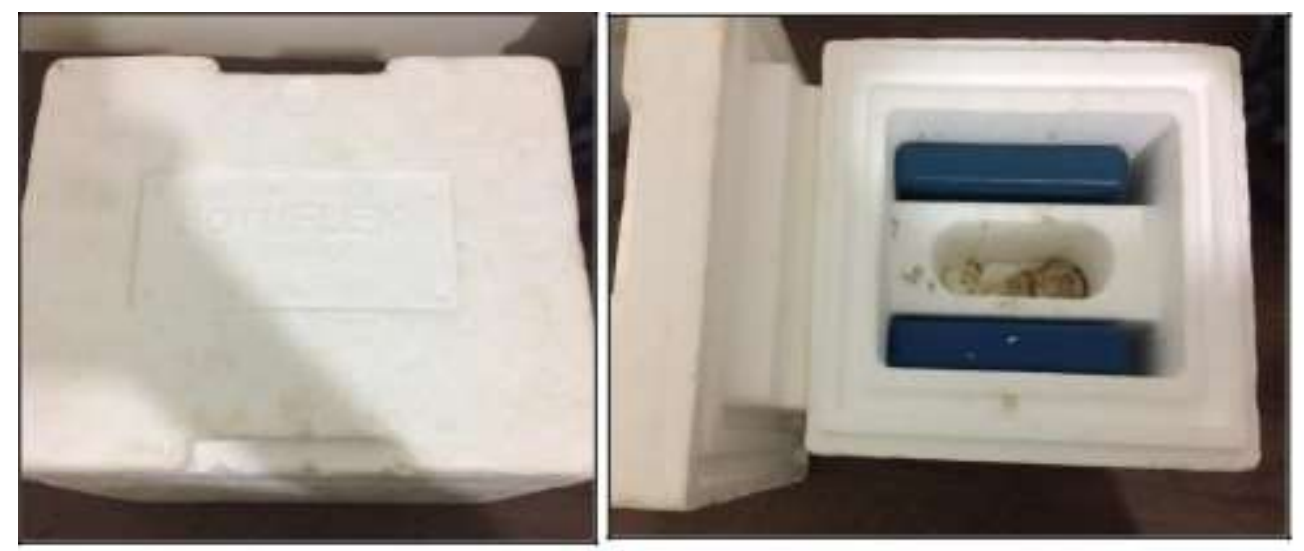

Fonte: Acervo pessoal. 
A caixa de transporte de sêmen refrigerado (Figura 6) tem como principal objetivo manter o sêmen a temperaturas mais amenas para que haja mais durabilidade da amostra, essas caixas de transporte podem manter a amostra seminal à $5^{\circ} \mathrm{C}$, a curva de resfriamento que acontece dentro dela é bem segura para que o espermatozoide não sofra choque térmico.

Figura 7. Laboratório para refrigeração e congelamento de sêmen.

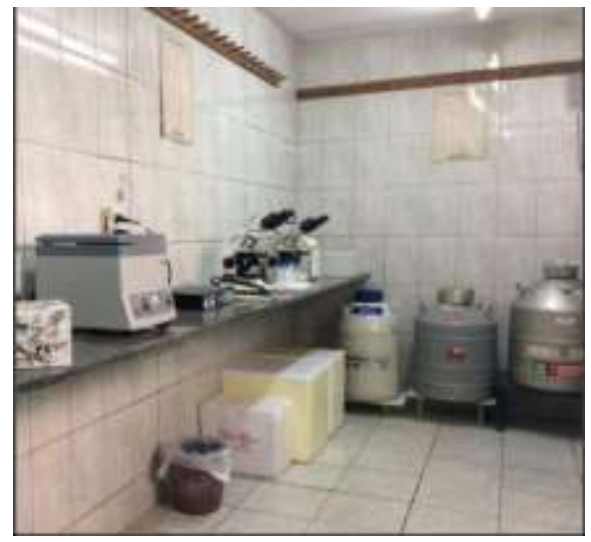

Fonte: Acervo pessoal.

O laboratório deve conter todo aparato necessário para que o processamento do sêmen seja feito com excelência, havendo maior aproveitamento do procedimento de criopreservação. Importante que o local seja ameno, seja um ambiente fácil de manejar as amostras sem que elas sejam totalmente processadas no mesmo local.

\subsection{Métodos de Congelação}

\subsubsection{Laboratório (Figura 7).}

Antes de iniciar a colheita do sêmen para congelação, deve-se:

- Preparar os materiais no laboratório ou sala onde será realizada a congelação;

$\square$ Observar a climatização do laboratório;

- Aferir a geladeira se está entre 4 e $6{ }^{\circ} \mathrm{C}$;

$\square$ Descongelar os diluentes e colocá-los no banho-maria a $37^{\circ} \mathrm{C}$;

- Separar microtubos de plásticos de $2 \mathrm{~mL}$ com 19 gotas ou $190 \mu \mathrm{L}$ de água destilada para a realização da concentração espermática.

\subsubsection{Cálculo de quantidade de palhetas}

Cada palheta deve conter 100 milhões de espermatozoides viáveis. Desta forma para o cálculo do número de palhetas basta dividir por 100 o número total de espermatozoides viáveis do ejaculado. São usadas de 5 a 8 palhetas por inseminação artificial o local de deposição pode ser no corpo ou no corno uterino.

\subsubsection{Centrifugação}

A centrifugação do sêmen diluído deve ser realizada para eliminar o plasma seminal a uma rotação de 2200 RPM/10 minutos (Figura 8). 
Figura 8. Centrifugação de amostra seminal.

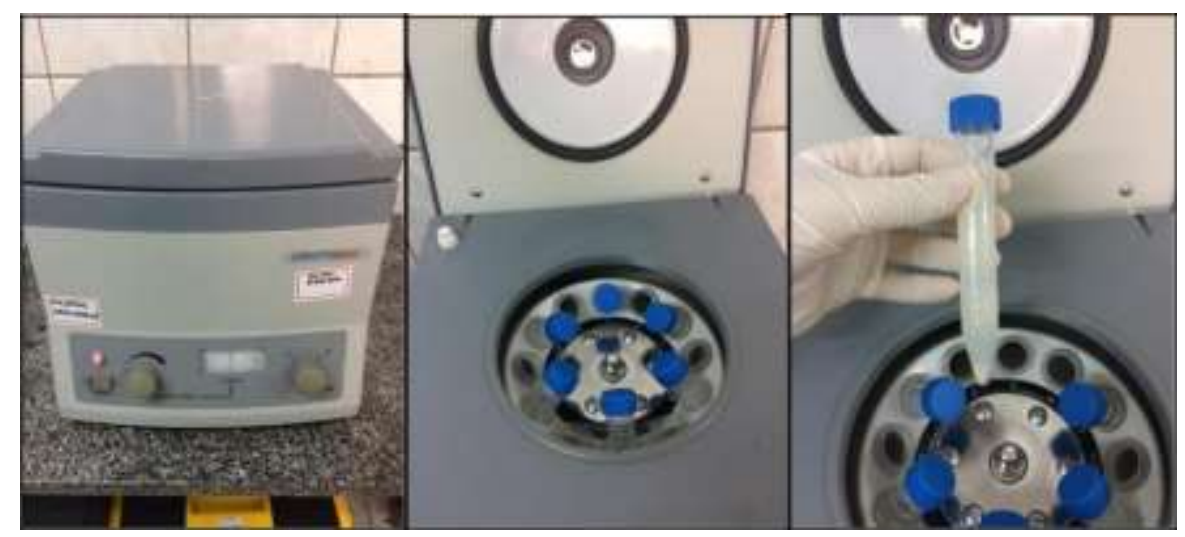

Fonte: Acervo pessoal.

\subsubsection{Ressuspensão e Envase das Palhetas}

O sobrenadante de cada frasco deve ser imediatamente desprezado e os "pellets" devem ser ressuspendidos no diluente de congelação. Logo após, faz-se o envase em palhetas de $0,5 \mathrm{~mL}$, sendo as mesmas lacradas com esferas metálicas (Figura 9).

Figura 9. Palhetas envasadas com sêmen na placa aquecedora, palhetes envasados em rampa de congelação.

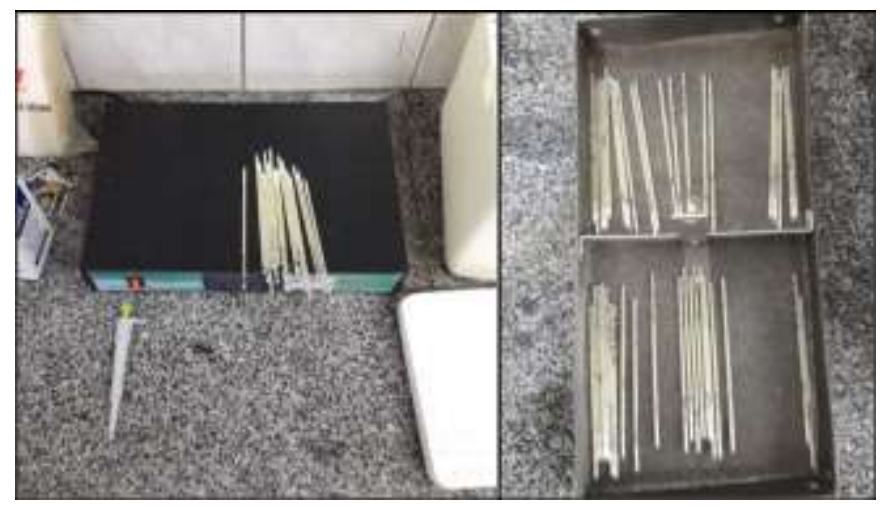

Fonte: Acervo pessoal.

As palhetas são envasadas com a amostra seminal, lacradas com esfera de metal. As mesmas devem ser mantidas na placa aquecedora para que a temperatura das amostras seminais se mantenha em constância. Após o envase de todas as palhetas, elas são colocadas na rampa de congelação (Figura 10) para que o congelamento se inicie (Figura 11).

\subsubsection{Estabilização}

Usando um termômetro digital, deve-se observar a temperatura interior da geladeira antes de iniciar o procedimento. A geladeira deve estar previamente estabilizada a $5{ }^{\circ} \mathrm{C}$, e as palhetas devem permanecer em seu interior por 20 minutos.

\subsubsection{Resfriamento rápido}

Em uma caixa isopor térmica tampada (37 a $45 \mathrm{~L}$ ), as palhetas devem ser colocadas em uma rampa de congelação (Figura 10) e ficar em média de 15 a 20 minutos em vapor de nitrogênio (manter as palhetas entre 3-6 cm acima do nível do nitrogênio líquido) (Figura 11). 


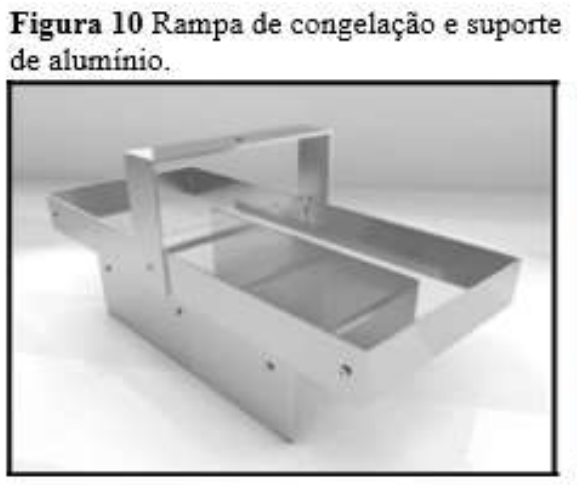

Fonte:www.botupharma.com.br/produto/k itcongelacaosemen/.

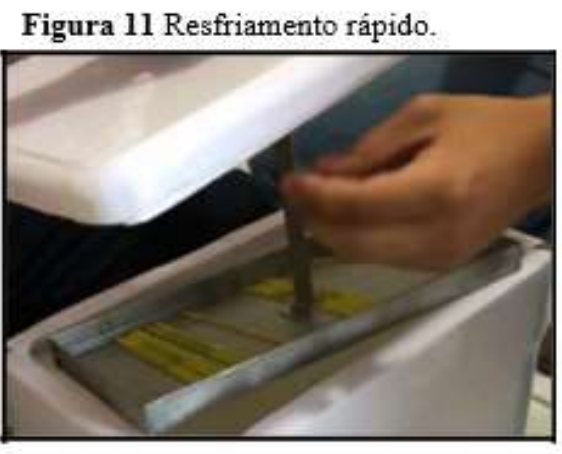

Fonte: Foto cedida por Centro de Reprodução Equina Jacob.

\subsubsection{Congelação}

Após o período de resfriamento rápido, deve-se realizar a imersão total das palhetas no nitrogênio líquido $\left(-196{ }^{\circ} \mathrm{C}\right)$ (Figura 12) e posteriormente, armazená-las em botijão criogênico.

Nota: Importante não tocar as palhetas durante o processo de congelação e armazenamento nas raques e canecas para evitar choque térmico causado pela temperatura corporal, manipular as palhetas com pinça.

Figura 12. Retirada de palhetas após imersão total no nitrogênio líquido.

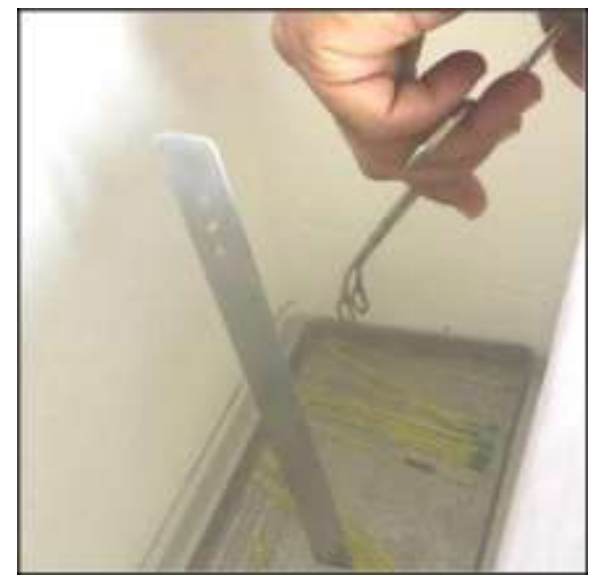

Fonte: Acervo pessoal.

Após imersão das palhetas em nitrogênio líquido é importante que a manipulação seja cuidadosa para que elas sejam colocadas no botijão criogênico. A retirada deve ser feita com pinça ou algum outro instrumental que facilite a retirada, a palheta não deve ter contato com a pele do manipulador para diminuir as chances de choque térmico nas amostras, e algum acidente ao manipulador.

\subsubsection{Descongelação}

A descongelação das palhetas é recomendável a utilização de temperatura entre $60^{\circ} \mathrm{Ce} 70^{\circ} \mathrm{C}$ durante 7 segundos em banho-maria. 


\section{Considerações Finais}

A utilização do sêmen refrigerado e congelado tem aumentado devido o desejo dos proprietários em ter o material genético dos seus animais disponível para uso posterior ou para venda das amostras criopreservadas (centrais de reprodução credenciadas no Ministério da Agricultura, Pecuária e Abastecimento - MAPA), mesmo se o reprodutor vier a óbito e também pelo fato da variação do momento da ovulação na espécie equina e, na maioria das vezes, para aumentar a variabilidade genética animal o sêmen utilizado é refrigerado advindo de propriedades distantes.

Caso o sêmen não esteja no momento ideal ou o mesmo chegue na propriedade após o esse período, uma solução é congelar o sêmen refrigerado, fazendo com que o mesmo seja armazenado por tempo indeterminado para evitar a sua perda, o projeto foi focado após 24 horas de refrigeração à $5{ }^{\circ} \mathrm{C}$, pois esse tempo é o suficiente para que aconteça o deslocamento do sêmen de uma propriedade distante, por exemplo.

Além disso, as amostras de sêmen podem ser transportadas no botijão criogênico, independente da distância, permitindo a criação de um banco genético na propriedade sem os gastos de mantença de vários reprodutores. Assim, é indicado que se utilizem reprodutores com melhor desempenho, tanto genético, quanto de qualidade seminal, para garantir maior eficiência reprodutiva e o rápido melhoramento genético do rebanho.

O estudo apresentado visa além de ajudar profissionais da área de reprodução equina, instigá-los a aprofundar cada vez mais a técnica de congelação do sêmen equino visando o aprimoramento e novos estudos voltados para essa biotecnologia. Desenvolvendo uma curva de congelamento mais eficaz, criando diluentes cada vez melhores e mais especializados no melhor resultado das amostras seminais que passaram pelo processo de criopreservação empregadas na inseminação artificial.

\section{Referências}

Aidar, N. B. Criopreservação de sêmen equino. Monografia - Universidade de Brasília - UnB/Faculdade de Agronomia e Medicina Veterinária, 2013.

Amann, R. P; Graham, J. K. (1993). Spermatozoal function. In: Mckinnon, A. O., Voss, J. L. Equine Reproduction. Lea \& Febiger.

Ashwood-Smith, M. J., Mechanisms of cryopro-tectant action. In: Bowler, K. \& Fuller, B. J. Temperature and Animal Cells. Cambridge: Biologists, 395 -406, 1987.

Ball, B. A, Medina V, Gravance C. G, \& Baumbe J. (2001). Effect of antioxidants on preservation of motility, viability and acrossomal integrity of equine spermatozoa during storage at 5 degrees C. Theriogenology, 56, 577-89.

Barreto, M. A. P., Silva, J. F. S., Fagundes, B., Caiado, J. R. C., Souza, G. V., \& Shimoya, A. (2008). Efeito de proteínas do plasma seminal equino com massa superior a $10 \mathrm{kDa}$ concentradas 10 vezes sobre a congelabilidade do sêmen. Revista Brasileira de Zootecnia, 37(12), 2115-2119.

Batellier, F., Vidament, M., Fauquant, J., \& Duchamp, G. (2001). Advances in cooled semen technology. Animal Reproduction Science, 68, 181-190.

Brito, L. F. C. (2007). Evaluation of stallion sperm morphology. Clin Techn Equine Pract. 6, 249-264.

Bruemmert, J. E., Coy, R. C., Squires, E. L., \& Grahan, J. K. (2002). Effect of pyruvate on the function of stallion spermatozoa storage for up to 48 hours. Journal of Animal Science, 80, 12-18.

Canisso, I. F., et al. (2008). Inseminação artificial em eqüinos: sêmen fresco, diluído, resfriado e transportado. Revista acadêmica: Ciências Agrárias e Ambientais, 6, (3), 389-398.

Canisso, I. F., et al. (2008). Congelamiento de semen de burro (Equusasinus). Revista de investigaciones veterinarias Del Perú, 19,113-125.

CBRA - Colégio Brasileiro De Reprodução Animal. Manual para exame andrológico e avaliação de sêmen animal. (3a ed.).

Cristanelli, M. J., Squires, E. L., Amann, R. P., et al. (1984). Fertility of stallion semen processed, frozen and thawed by a new procedure. Theriogenology, 22, (1), 39-45.

Darenius, A. Experiences with chilled, transported equine semen. In: Stallion Reproduction Symposium, 1998. Proceedings... Montgomery, AL: Society for Theriogenology, American Association of Equine Practitioners, 60-70.

Dell'aqua JR, J. A. Efeito da centrifugação, tipos de envase e temperatura de descongelamento sobre os parâmetros espermáticos e índices de fertilidade relacionados com o local de 37 deposição e concentração da dose inseminante do sêmen congelado equino. Dissertação (Mestrado), 2000.

De Vita, B. (2006). Biotecnologia e inseminação artificial com sêmen congelado equino. Monografia (Mestrado) - Faculdade de Medicina Veterinária e Zootecnia, Universidade Estadual Paulista, Botucatu. 
Fürst, R., Carvalho, G. R., Fürst, M. C. O., Ruas, J. R. M., Borges, A. M., \& Mafilli, V. (2005). Efeito do resfriamento do sêmen equino 38 sobre sua congelabilidade. Arq. Bras. Med. Vet. Zootec, 57(5), 599- 607.

Fürst, R. (2006). Efeito de diferentes tempos de equilíbrio, taxas de congelamento e concentrações espermáticas na fertilidade do sêmen equino. 96 f. Tese (Doutorado em Zootecnia) - Departamento de Zootecnia, Universidade Federal de Viçosa, Viçosa.

Heitland, A. V., Jasko, D. J., Graham, J. K., Squires, E. L., Amann, R. P., \& Pickett, B. W. Motility and fertility of stallion spermatozoa cooled and frozen in a modified skim milk extender containing egg yolk and liposome. Biol Reprod Mono, 1, 753-759, 1995.

Holt, W. V. Basic aspects of frozen storage of semen. Animal Reproduction Science. 62, 3-22, 2000.

Jasko, D. J. (1934). Procedures for cooling and freezing of equine semen. ARS Veterinária, 10, 156-165.

Jondet, M; Dominique, S; Scholler, R. Effects of freezing and thawing on mammalian oocyte. Cryobiology, 21, 192-199.

Keith, S. L. Evaluation of new cryoprtectants for the preservation of equine spermatozoa. Tese (Doutorado) - Colorado StateUniversity, 1998.

Lima, R. A. S., Oliveira, R. A., Mendes, C. Q., \& Júnior, P. G. Perfil e Tendências da Equideocultura Brasileira. Anais da 49a Reunião Anual 40 da Sociedade Brasileira de Zootecnia. A produção animal no mundo em transformação. Brasília, 23 a 26 de julho de 2012.

Loomis, P. R. (2006). Advanced methods for handling and preparation of stallion Semen. Veterinary Clinics North American Equine Practice, 22(3), 663-676.

Mazur, P. (1970). Cryobiology: The freezing of biological systems. Science, 199, 939- 949.

Mazur, P. Basic concepts in freezing cell. In: Deep freezing of boar semen, 1985, Uppsala. Proceedings. Uppsala, $1985,199-222$.

Mckinnon, A. O. Artificial insemination of cooled, transported and frozen semen. Australian Equine Veterinarian, 14(4), 156-174.

Mies Filho, A. (1987). Reprodução dos Animais Domésticos. (6a ed.), Sulina, 115-119.

Moran, D. M., Jasko, D. J., Squires, E. L., et al. (1992). Determination of temperature and cooling rate which induce cold shock in stallion spermatozoa. Theriogenology, 38, 999-1012.

Papa, F. O. et al. Methodological innovations in the biotechnology cooled and freezing of equine semen. Acta Scientiae Veterinariae, 33, 19- 27, 2005. Suppl. 1.42

Parks, J. E., \& Graham, J. K. (1992). Effects of cryopreservation procedures on sperm membranes. Theriogenology, 38, $209-222$.

Pereira, A. S., et al. (2018). Metodologia da pesquisa científica. Ed. UAB/NTE/UFSM. https://repositorio.ufsm.br/bitstream/handle/1/15824/Lic_C omputacao_Metodologia-Pesquisa-Cientifica.pdf?sequence=1.

Pimentel, C. A., \& Carneiro, G. F. Biotecnias Aplicadas à Reprodução de Equinos. In: Gonçalves, B. D. G., Figueiredo, R. F., Freitas, V. J. F. (2a ed.), Biotécnicas aplicada à Reprodução Animal, São Paulo: Roca, 2008, 145-159.

Pugliesi, G. Viabilidade e fertilidade do sêmen equino resfriado a $5{ }^{\circ} \mathrm{C}$ por 24 horas com dois diluentes. Dissertação de Mestrado. Universidade federal de Viçosa, Viçosa/MG, 103p, 2009.

Raphael, C. F. Efeitos da centrifugação nas características de movimento, integridade e peroxidação lipídica das membranas do espermatozóide equino refrigerado. 2007. 111 f. São Paulo. Dissertação (Mestrado em Reprodução Animal) - Faculdade de Medicina Veterinária e Zootecnia da Universidade de São Paulo, São Paulo, 2007.

Silva Filho, J. M. et al. (1997). Fertilidade do sêmen equino diluído, resfriado e transportado. Revista Brasileira de Zootecnia, 26(6), $1134-1141$.

Snoeck, P. P. N. et al. (2007). Efeito de diferentes diluidores sobre a viabilidade espermática pós-descongelação de sêmen equino. Arquivo Brasileiro de Medicina Veterinária e Zootecnia, 59(1).

Watson, P. F. (2000). The causes of reduced fertility with cryopreserved semen. Animal Reproduction Science, 60-61, 481-492.

Valle, G. R., Silva Filho, J. M., Palhares, M. S., et al. (1999)). Utilização de um container modelo CELLE modificado para resfriamento e transporte de sêmen equino. Arquivo brasileiro de Medicina Veterinária e Zootecnia, 51, 505-514.

Zimmermann, M. F. Efeito da diluição do crioprotetor dimetilformamida de amostras em sêmen equino descongeladas utilizando-se dois diluentes comerciais. Dissertação (Mestrado) - Universidade de Brasília - UnB/Faculdade de Agronomia e Medicina Veterinária, 2007. 